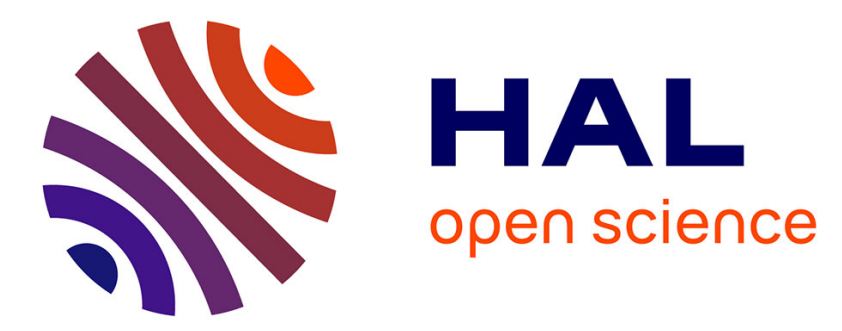

\title{
Kinetics of thin polymer film rupture: Model experiments for a better understanding of layer breakups in the multilayer coextrusion process
}

Yann Zhu, Adrien Bironeau, Frédéric Restagno, Cyrille Sollogoub, Guillaume

Miquelard-Garnier

\section{To cite this version:}

Yann Zhu, Adrien Bironeau, Frédéric Restagno, Cyrille Sollogoub, Guillaume Miquelard-Garnier. Kinetics of thin polymer film rupture: Model experiments for a better understanding of layer breakups in the multilayer coextrusion process. Polymer, 2016, 90, pp.156-164. 10.1016/j.polymer.2016.03.005 . hal-02270658

\section{HAL Id: hal-02270658 \\ https://hal.science/hal-02270658}

Submitted on 28 Aug 2019

HAL is a multi-disciplinary open access archive for the deposit and dissemination of scientific research documents, whether they are published or not. The documents may come from teaching and research institutions in France or abroad, or from public or private research centers.
L'archive ouverte pluridisciplinaire HAL, est destinée au dépôt et à la diffusion de documents scientifiques de niveau recherche, publiés ou non, émanant des établissements d'enseignement et de recherche français ou étrangers, des laboratoires publics ou privés. 


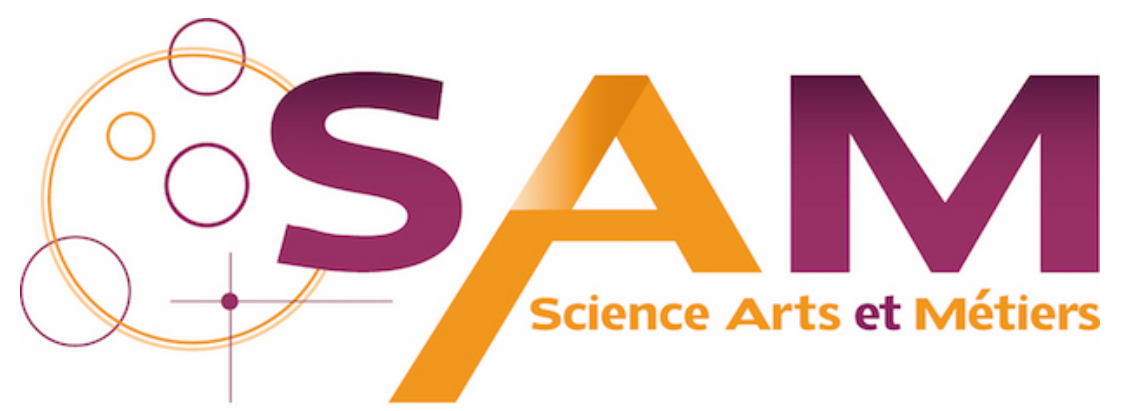

Archive Ouverte - Open Repository

\section{Science Arts \& Métiers (SAM)}

is an open access repository that collects the work of Arts et Métiers ParisTech researchers and makes it freely available over the web where possible.

This is an author-deposited version published in: https://sam.ensam.eu Handle ID: .http://hdl.handle.net/10985/16016

\section{To cite this version :}

Yann ZHU, Adrien BIRONEAU, Frédéric RESTAGNO, Cyrille SOLLOGOUB, Guillaume MIQUELARD-GARNIER - Kinetics of thin polymer film rupture: Model experiments for a better understanding of layer breakups in the multilayer coextrusion process - Polymer - Vol. Volume 90, p.Pages 156-164-2016 


\title{
Kinetics of thin polymer film rupture: Model experiments for a better understanding of layer breakups in the multilayer coextrusion process
}

\author{
Y. Zhu a ${ }^{a}$, A. Bironeau ${ }^{\text {a }}$, F. Restagno ${ }^{\text {b }}$, C. Sollogoub ${ }^{\text {a }}$, G. Miquelard-Garnier ${ }^{\text {a, * }}$ \\ a PIMM Lab, UMR 8006, ENSAM, CNAM, CNRS, 151 Boulevard de l'Hôpital, 75013 Paris, France \\ ${ }^{\mathrm{b}}$ Laboratoire de Physique des Solides, CNRS, Univ. Paris-Sud, Université Paris-Saclay, 91405 Orsay Cedex, France
}

\begin{abstract}
A B S T R A C T
We show that the kinetics of bursting of a thin film embedded in another polymer matrix can be well described by a simple equation balancing the viscous and capillary forces. The role of viscosity, interfacial tension and thickness of the layers under static conditions was investigated by adapting a simple model experiment initially designed to study the dewetting of a thin polymer film on another polymer substrate. Kinetics was correlated to instabilities occurring during multilayer coextrusion leading to the break-up of layers below a critical nanometric thickness. The results suggest that shear and elongation forces during the process actually stabilize the layers. Understanding these instabilities is of great interest since this innovative process showed potential to design at an industrial scale macromolecular materials displaying new macroscopic properties, due to interfacial and confinement effects. However, instabilities leading to the breaking of these nanometric layers will alter final properties (optical, gas barrier ...).
\end{abstract}

\section{Introduction}

The need of new specialty polymeric materials goes through developments of new molecules via organic chemistry [1,2] but also a better control of the materials architecture at every scale especially via the industrial processes [3].

Multilayer coextrusion is an innovative process derived from classical co-extrusion which is industrially relevant. Starting from two $(A B)$ or 3 layers ( $A B A)$ of polymers $A$ and $B$, and by forcing the polymer flows through a series of multiplying elements, one can achieve materials (especially films) made of thousands of alternating $A$ and $B$ layers, in which all the layers have nanometric thicknesses (see Fig. 1) while the total thickness of the material is millimetric.

This processing tool has been patented roughly 40 years ago [4] and used industrially to produce iridescent films. It has then been widely studied by the group of E. Baer in Case Western University over the last twenty years [5]. They showed lots of potential applications for polymeric materials prepared using this so called "forced assembly" technique [6-10]. This is due to the fact that many properties (mechanical, electrical conductivity, gas barrier)

\footnotetext{
* Corresponding author.

E-mail address: guillaume.miquelardgarnier@lecnam.net (G. MiquelardGarnier).
}

can be greatly improved due to the confinement of the polymers within the nanometric layers (which can for example modify the crystallization of these polymers) and the multiplication of the interfaces and thus interphases. It was also developed and used in our lab especially for the design of new nanocomposites [11,12] and nanoblends $[13,14]$.

However, it has observed in some cases (or more specifically for some couples of polymers A and B) that the layers breakup when trying to reduce the layer thickness down to around $10 \mathrm{~nm}$ : polypropylene (PP) and polyethylene oxide (PEO) [15], polystyrene (PS) and polyethylene (PE) [16], polyethylene terephtalate (PET) and polycarbonate (PC) [17], polypropylene and PC [18]. It has also been observed in our group for PS and poly(methyl methacrylate) (PMMA) (see Fig. 1). These results seem to reveal the existence of a critical thickness below which a spontaneous breakup of the layers occurs. It has been shown that such breakups might affect properties of the resulting material, such as gas barrier properties [10]. The physical origin of the instabilities occurring during the multilayer coextrusion and leading to these break-ups, nonetheless, has not been discussed in details to the best of our knowledge.

On the other hand, interfacial instabilities during classical coextrusion have been examined quite extensively $[19,20]$. These studies have pointed out the existence of critical conditions for the onset of those instabilities at the microscale, in terms of viscoelastic properties of the two polymers. However, during multilayer 

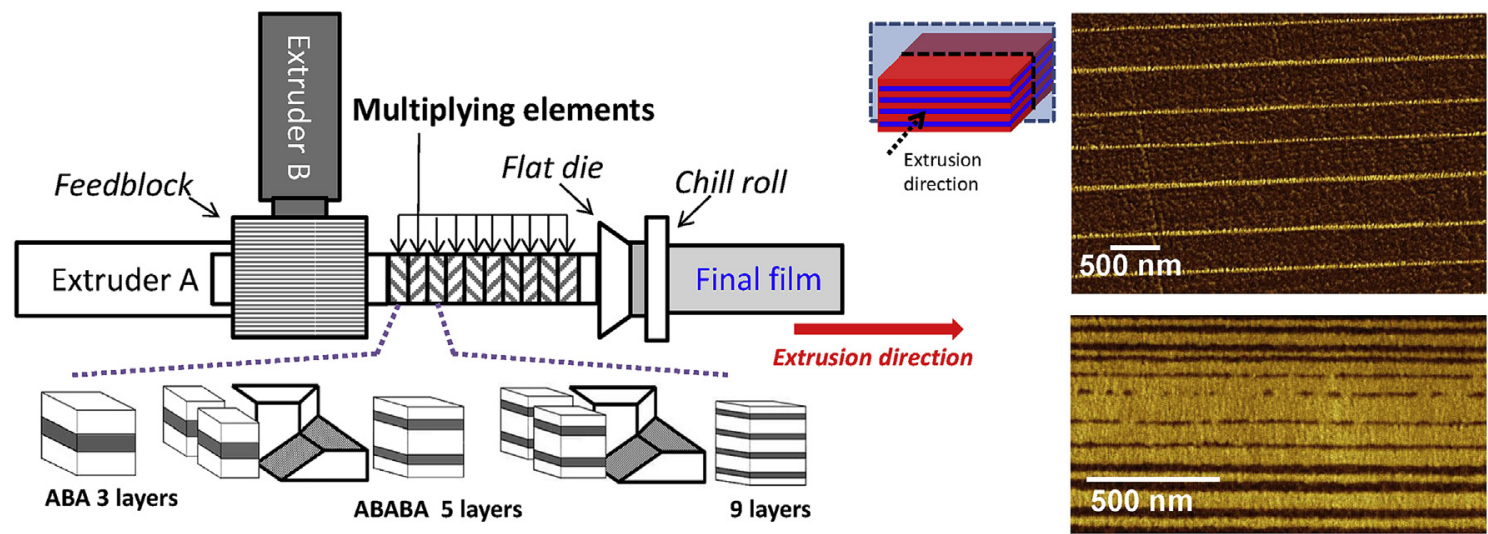

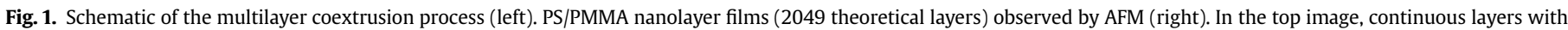

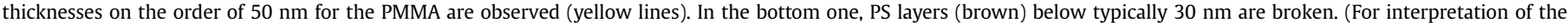
references to colour in this figure legend, the reader is referred to the web version of this article.)

coextrusion, the instabilities leading to breakups of layers only appear in the nanometric range of thicknesses. An ongoing study in our group shows moreover that these instabilities can be seen in PS/PMMA when reducing the layer thicknesses and whatever the processing conditions chosen, even those favoring stable layers at the microscale (similar viscosities and elasticities in the extrusion range of shear rates [19]). These results suggest then that the instabilities in the nanolayer coextrusion may be from another nature and rather related to molecular parameters (size of the molecules, Flory interaction parameter, interfacial tension ...). In consequence, a deeper understanding of the reason(s) for these instabilities, these layers breakups and the existence of a critical thickness is necessary to achieve a sufficient control of the process in order to design new polymeric materials with enhanced properties.

Trying to decouple these effects, one can look, in a first approach, at a model experiment in a "static" mode where only the polymers physical parameters are playing a role.

For example, "static" (e.g. with no external flow applied) dewetting of thin polymer films on polymer substrates has been widely studied over the past 20 years, both theoretically, mainly by Brochard-Wyart et al. [21], and experimentally after the pioneering work of Reiter on silicon substrates [22], mostly with PS and PMMA [23-27]. Indeed, when a thin (below $\sim 1 \mu \mathrm{m}$ ) polystyrene (PS) film is deposited on top of a PMMA substrate, the film promptly dewets when heated above its glass transition temperature because the spreading parameter is negative. As will be discussed in more details below, several regimes which will influence the dynamics of dewetting can be expected and have been observed experimentally [23-26], mainly due to the viscosity ratio and the surface and interfacial tensions of the two polymers at the chosen temperature.

A more representative "static" experiment of what happens during the multilayer coextrusion would be the rupture of a polymer thin film within two thicker layers of another polymer, e.g. two polymer-polymer interfaces (instead of one polymer-polymer interface and one polymer-air interface). The dewetting kinetics of such systems has not been studied yet, though one recent paper dealt with the onset of the instabilities within a PS-PMMA-PS thin sandwich [28]. The closest experiments were actually those conducted by Reyssat and Quéré on the bursting of a water film within an oil bath, with the difference that in the polymer-polymer case viscosities are both very high and may also be of similar values [29].

In consequence, we developed in this study an experimental setup allowing to follow the rupture kinetics of thin polymer films for both bilayers systems (thin PS film on PMMA substrate) and trilayers systems (thin PS in between two thicker PMMA layers) heated above $T_{g}$ with no external flow applied. We compare the results quantitatively to both theoretical and experimental work from the literature. We show that the dewetting/bursting speed of this trilayer system can be very well described by a simple model adapted from Reyssat and Quéré [29]. We finally compare the results with the typical processing time in multilayer coextrusion to show that the dynamics within the process actually probably act as a stabilizing effect for obtaining continuous layers within the materials.

\section{Experimental section}

Commercial extrusion grades of PS and PMMA used for multilayer coextrusion (e.g. highly formulated polymers with relatively large weight distribution) were chosen for this study, namely PS 1340 provided by Total and PMMA VM100. Another more viscous grade, PMMA V825T was also used in this study. Both PMMA samples were gratefully supplied by Arkema. The melt flow indexes (MFI) are, as given by the suppliers, $4 \mathrm{~g} / 10 \mathrm{~min}$ at $200^{\circ} \mathrm{C} / 5 \mathrm{~kg}$ for PS $1340,14.5 \mathrm{~g} / 10 \mathrm{~min}$ and $2.8 \mathrm{~g} / 10 \mathrm{~min}$ for PMMA VM100 and V825T respectively, at $230{ }^{\circ} \mathrm{C} / 3.8 \mathrm{~kg}$. The molar masses and dispersity $Ð$ (defined as $\mathrm{M}_{\mathrm{w}} / \mathrm{M}_{\mathrm{n}}$ ) were measured by GPC (Agilent $220 \mathrm{HT}$ ) in tetrahydrofuran (THF) using PS standards for the PS while PMMA standards were used for the PMMA. Results are summarized in Table 1.

The complex viscosity was determined using an Anton Paar rheometer at several temperatures $\left(180^{\circ} \mathrm{C}, 200^{\circ} \mathrm{C}\right.$ and $\left.225^{\circ} \mathrm{C}\right)$ with a frequency sweep test $(0.01 \mathrm{~Hz}-100 \mathrm{~Hz}$ at $1 \%$ strain). The plateau value of the viscosity at low frequencies was either obtained directly or by fitting the obtained curves using the Carreau-Yasuda equation if the plateau could not be observed (which was the case especially at $180{ }^{\circ} \mathrm{C}$ ). Values are listed in Table 1 for the three polymers studied.

It is worth noting that at the extrusion temperatures used in the group for the fabrication of PS/PMMA nanolayered films $\left(200^{\circ} \mathrm{C}\right.$ or

Table 1

Molar masses and rheological values for various temperatures of the polymers used in the study.

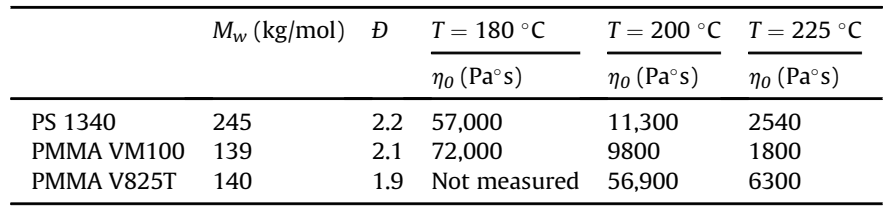


$225^{\circ} \mathrm{C}$ ) and with the materials chosen (PS 1340 and PMMA VM100), the viscosity ratio of the two polymers remains close to 1 (1.2 at $200{ }^{\circ} \mathrm{C}$ and 1.4 at $225{ }^{\circ} \mathrm{C}$ for $\eta_{0} \mathrm{PS} / \eta_{0}$ PMMA $)$. Moreover, at these temperatures and at the typical shear rates found in the extruders (in the $1-10 \mathrm{~s}^{-1}$ range) the elasticity ratio $\left(G_{\mathrm{PS}}^{\prime} / G_{\text {PMMA }}^{\prime}\right)$ also remains close to 1 (between 0.5 and 2).

Here, we should state that in most of the previous studies $[24,25,27]$ the viscosity was indeed not measured but calculated using relationships such as $\eta \propto M_{w}^{3.4}$ and the Vogel-FulcherTamman equation with constants values taken from the literature. In these studies, it appears that, for similar molar masses, PMMA is much more viscous than PS. As stated before, the materials chosen here, for means of comparisons with the multilayer coextruded systems, are commercial grades with relatively high $Ð$ (leading to uncertainties for calculated values of viscosity) and the presence of plasticizing agents which will affect the viscosity. Finally, the large differences observed for the two PMMA despite the fact that molar masses and $\emptyset$ are similar can be explained the same way.

PMMA substrates were obtained via spin-coating (Spin $150 \mathrm{v}-3$ from SPS) of a PMMA solution in toluene (20\% wt for the VM100 and $15 \%$ for the V825T) on a glass slide. The speed and acceleration were fixed $\left(2000 \mathrm{rpm}\right.$ and $1000 \mathrm{r} / \mathrm{s}^{2}$ for the VM100, $1000 \mathrm{rpm}$ and $1000 \mathrm{r} / \mathrm{s}^{2}$ ): the resulting thickness was close to $3 \mu \mathrm{m}$. The precise thickness was each time measured using a Veeco Profilometer (Dektak 150). The mean square roughness of the PMMA samples was also verified and is less than $1 \mathrm{~nm}$ for a $100 \mu \mathrm{m}$ scan. Any possible impact of the roughness of the substrate on the dewetting was neglected in this study [30]. Complementary substrates with thicknesses close to $400 \mathrm{~nm}$ and $10 \mu \mathrm{m}$ were obtained by changing the solutions concentrations and spin-coating parameters $(6.7 \% \mathrm{wt}$ solution of VM100 spin coated at $2000 \mathrm{rpm}$ and $4000 \mathrm{r} / \mathrm{s}^{2}$, and $8 \%$ wt solution of V825T spin coated at $2000 \mathrm{rpm}$ and $1000 \mathrm{r} / \mathrm{s}^{2}$ for $400 \mathrm{~nm} ; 28 \%$ wt solution of VM100 spin coated at $1000 \mathrm{rpm}$ and $1000 \mathrm{r} / \mathrm{s}^{2}$, and $25 \%$ wt solution of V825T spin coated at $1000 \mathrm{rpm}$ and $1000 \mathrm{r} / \mathrm{s}^{2}$ for thicknesses of 12 and $10 \mu \mathrm{m}$ respectively). Thicker substrates $(>100 \mu \mathrm{m})$ were obtained using pellets put under a thermocompression press (Laboratory Press, Gibrite Instruments) set at 100 bar and $225^{\circ} \mathrm{C}$ for $3 \mathrm{~min}$.

PS thin films were prepared via spin-coating of PS solutions in toluene on a silicon wafer treated 5 min in a UV-ozone chamber. By varying the concentration of PS in the toluene (from 1 to $4 \% \mathrm{wt}$ ) and the speed of spin-coating (from 2000 to $3000 \mathrm{rpm}$ ) while keeping the acceleration constant $\left(4000 \mathrm{r} / \mathrm{s}^{2}\right)$, three thicknesses were achieved and studied: $50 \mathrm{~nm}, 120 \mathrm{~nm}$, and $260 \mathrm{~nm}$. The exact thickness was for each sample controlled using an Atomic Force Microscope AFM (Veeco Nanoscope V) in tapping mode, using tips (Tap300-G; force constant: $40 \mathrm{~N} / \mathrm{m}$, resonance frequency: $300 \mathrm{kHz}$, tip radius $<10 \mathrm{~nm}$ ) obtained from Budget Sensors (Sofia, Bulgaria). The samples were scratched using a razor blade and the thicknesses measured via the Nanoscope v7.1 software.

After spin-coating, the films were cut in small pieces using a razor blade and then floated on a distilled water bath. No annealing was performed in the samples, similar to what was done in Refs. [24-26] The choice not to anneal the PS thin film (and neglecting the potential impact the kinetics of the instabilities growth) was based on the fact that during extrusion, polymer chains are also strongly out of equilibrium in terms of conformation.

To prepare the bilayer systems, the PS film was then simply picked up on the PMMA substrate and let a few hours under open air to remove the remaining water. To prepare the trilayer systems, same procedure was applied. Then, another PMMA substrate on a glass slide was put on top of the bilayer and put at $150{ }^{\circ} \mathrm{C}$ for $2 \mathrm{~min}$ with a small force applied on top to ensure adhesion between the two PMMA without inducing significant flow of the polymers resulting in a change of thicknesses. At this temperature, it was verified that no dewetting of the PS occurs in this time scale (dewetting actually only occurs after more than $6 \mathrm{~h}$ at $150{ }^{\circ} \mathrm{C}$ ). Rather than a real trilayer system, this is actually more a PS thin film embedded in a PMMA matrix.

The bilayer or trilayer systems were then put in a Mettler FP80 heating stage already set at the chosen temperature $\left(180^{\circ} \mathrm{C}\right.$, $200{ }^{\circ} \mathrm{C}$ or $225^{\circ} \mathrm{C}$ ) under an Olympus BH-2 optical microscope with a $10 \times$ magnification (or $20 \times$ magnification for the thinner films or the higher temperatures) (see Fig. 2). Note that with this setup, the instabilities are observed from the top, while the AFM observations on multilayer films in Fig. 1 are made from the side of the film (eg in the extrusion direction). After the focus is made manually (which takes between $30 \mathrm{~s}$ and $1 \mathrm{~min}$ ), images were taken at regular times depending on the speed of the experiment (depending on the experimental conditions, from a few minutes to a few hours to have coalescence of the holes into droplets) to observe the appearance of holes in the PS and their growth over time. Contrary to many experimental set-up used in the literature (references [24,25] for example) and since we are not interested here in probing the shape of the rim, the setup chosen here enables to follow in situ the dewetting, without quenching of the sample and possible issues in the data analysis due for example to non-constant viscosity while heating and then quenching.

For each experiment, at least 5 images taken at different times were analyzed. On these images, the growth of at least 3 holes was followed. Holes were chosen so that there are no surrounding holes closer than typically the diameter of the hole: in consequence, the possible interactions between holes were neglected in the analysis. The final stage of the dewetting process (coalescence of the holes to form droplets) was not studied here. At least two samples were studied for each set of fixed parameters (namely temperature, PS and PMMA thicknesses). The inner diameter of the holes was then measured using the Olympus analysis software with a typical precision of $\pm 0.5 \mu \mathrm{m}$.

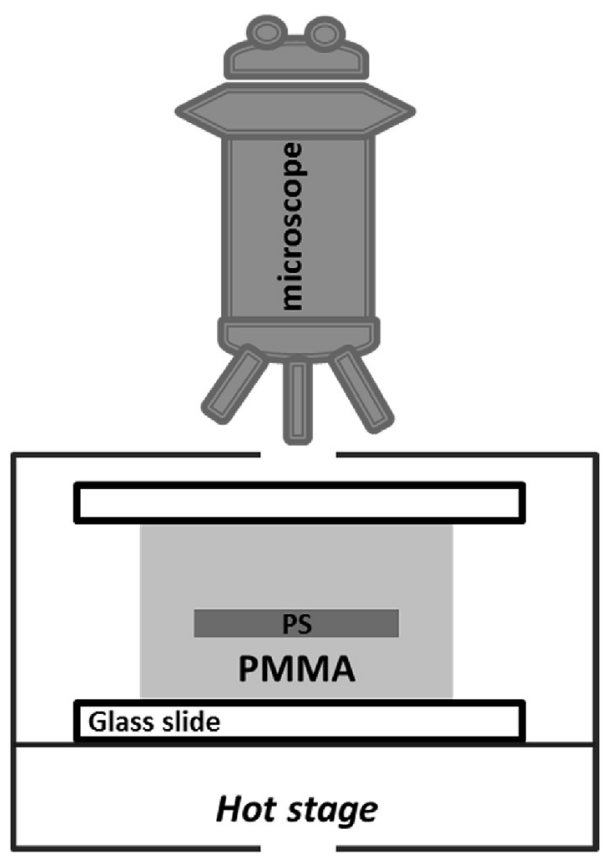

Fig. 2. Schematic of the experiment for a "trilayer" system. 


\section{Results and discussion}

\subsection{Bilayer system}

First, bilayers were tested using the experimental set-up and the obtained results were compared to theoretical models and experimental data from the literature.

PS stability on a PMMA film can be calculated using the spreading parameter $S$ which compares the PMMA surface tension $\gamma_{\text {PMMA }}$ to the sum of the PS surface tension $\gamma_{\text {PS }}$ and the PS/PMMA interfacial tension $\gamma_{\text {PS }}$ PMMA. PS will spontaneously dewet on PMMA (below a critical thickness depending on the capillary length $\sim 1 \mathrm{~mm}$ ) since the spreading parameter (equation (1)) is negative at the three temperatures studied, using for example values reported by $\mathrm{Wu}$ and the linear interpolation of its data as a function of the temperature [31], respectively $\gamma_{\mathrm{PMMA}}=41.1-0.076 \times(T-20)$, $\gamma_{P S}=40.7-0.072 \times(T-20)$ and $\gamma_{P S} /$ PMMA $=3.2-0.013 \times(T-20)$, in $\mathrm{mJ} / \mathrm{m}^{2}$.

$S=\gamma_{\text {PMMA }}-\left(\gamma_{\text {PS }}+\gamma_{\text {PS } / \text { PMMA }}\right)$

Using these values, we obtain $S=-1.04 \mathrm{~mJ} / \mathrm{m}^{2}$ at $225{ }^{\circ} \mathrm{C}$, $S=-1.25 \mathrm{~mJ} / \mathrm{m}^{2}$ at $200{ }^{\circ} \mathrm{C}$ and $S=-1.33 \mathrm{~mJ} / \mathrm{m}^{2}$ at $180^{\circ} \mathrm{C}$.

Below a thickness on the order of $1 \mu \mathrm{m}$ (balancing the capillary length with the molecular length of the system), the PS film will in that case [25] dewet by a mechanism of nucleation and growth of holes, either due to homogeneous (thermal) or heterogeneous (caused by the presence of defects or dusts in the film) nucleation. We should note here that another mechanism for the appearance of the holes (spinodal dewetting) exists and that the parameters governing each mechanism have been discussed in details in the literature [27,32]. However, as stated in reference, [23] the dynamics of hole formation is not affected by the originating mechanism of film rupture and thus will not be discussed further in this article.

Once the holes are formed and start to grow, several scenarios are possible, depending on the viscosity ratio between the film and the substrate, the ratio between the thickness of the substrate and the size of the rim, and the surface and interfacial tensions of the polymers $[21,23]$.

\subsubsection{Liquid-liquid dewetting}

If $\eta_{P M M A}<\eta_{P S} / \theta_{e}$, where $\theta_{e}$ is the equilibrium contact angle which can be estimated using equation (2) in the small angle approximation, and is on the order of 0.4 (similar to values reported in the literature, for example 0.2 at $162{ }^{\circ} \mathrm{C}$ in reference ${ }^{24}$ ), we are in the liquid-liquid dewetting case.

$S=-\frac{1}{2} \gamma \theta_{e}^{2}$

$\gamma$ being an effective surface tension given by $1 / \gamma=1 / \gamma_{\mathrm{PS}}+1 /$ $\gamma_{\text {PMMA }}$ (see reference [23]).

This is the case for the substrate PMMA VM100 at the 3 temperatures studied. In this case, the viscous dissipation is dominated by the contribution of the substrate. If the substrate is very thick, the size of the holes grows linearly with time, e.g. the dewetting velocity is constant.

This behavior changes when the thickness of the substrate becomes comparable to the size of the rim, which is the case in our study since the lateral size of the rim is $\sim 1-2 \mu \mathrm{m}$ (assumed to be the darker line at the edge of the hole, see Fig. 3 ). The dewetting velocity then becomes time $(t)$ dependent, following the equation predicted by Brochard-Wyart [21] (equation. (3)) $\left.v=\frac{2}{3} \frac{\gamma^{2} d_{\mathrm{PMMA}}^{2} \theta_{e}}{\eta_{\mathrm{PMMA}}{ }^{2} d_{\mathrm{PS}}}\right)^{1 / 3} t^{-1 / 3}$

where $d_{\text {PMMA }}$ and $d_{\text {PS }}$ are the thicknesses of the PMMA substrate and the PS film respectively, and $\eta_{\text {PMMA }}$ the viscosity of the substrate.

Following equation (3), the size of the hole grows with time according to equation (4) (equation (4))

$\left.R=t^{2 / 3} \frac{\gamma^{2} d_{\mathrm{PMMA}}^{2} \theta_{e}}{\eta_{\mathrm{PMMA}^{2} d_{\mathrm{PS}}}}\right)^{1 / 3}$

$R$ being the radius of the hole.

Fig. 3 displays the typical growth of a hole in a bilayer system, with a PS film of thickness $260 \mathrm{~nm}$ on a PMMA substrate of thickness $3 \mu \mathrm{m}$ at $200{ }^{\circ} \mathrm{C}$.

As discussed in reference, [25] we introduce $t_{0}$ as a fitting parameter since, as can be seen in the pictures on the right, holes do not all appear at the beginning of the experiment, nor exactly at the same time (nucleation), which is not predicted in Brochard-Wyart's model. As can be seen on the left, the data points are well fitted by the model, fixing $2 / 3$ as the exponent. The floating parameters are then $a$ and $t_{0}$ and the values obtained are $3.28 \times 10^{-7} \mathrm{~m} \mathrm{~s}^{-2 / 3}$ and $97 \mathrm{~s}$ respectively. By not fixing the exponent, the best fit is obtained for an exponent of 0.72 , in very good agreement with the predicted $2 / 3$ dependence over time. Similar values as previously are also obtained for $a$ and $t_{0}\left(2.27 \times 10^{-7} \mathrm{~m} \mathrm{~s}^{-2 / 3}\right.$ and $73 \mathrm{~s}$ respectively $)$. In consequence, in the following, $2 / 3$ is chosen to be a fixed parameter for the fits. It is noteworthy that to get more precise evaluation of the fit, one should follow the hole growth for longer times, which is prevented by the fact that too many holes appear rapidly in the sample to look at isolated ones over long times (as can be seen on the top right of the pictures in Fig. 2).

Fig. 4 shows the time dependence of the holes' growth for 6 different holes on 2 different samples tested in the same condition as above. One can see that the fits work very well and allow obtaining an average "initiation time" $t_{0}$ for the holes, $143 \pm 23 \mathrm{~s}$ in the experimental conditions presented here. It also gives an experimental value for the parameter given in equation (4),

$$
\left.\frac{\gamma^{2} d_{\mathrm{PMMA}}^{2} \theta_{e}}{\eta_{\mathrm{PMMA}} d_{\mathrm{PS}}}\right)^{1 / 3} \text {. }
$$

In these conditions (for this particular experimental condition, a total of 15 holes on 5 samples was measured), this value is $3.39 \times 10^{-7} \pm\left(1.2 \times 10^{-8}\right) \mathrm{m} \mathrm{s}^{-2 / 3}$. The theoretical value gives $2.65 \times 10^{-6} \mathrm{~m} \mathrm{~s}^{-2 / 3}$, close to 8 times higher than the experimental value. Though a bit bigger difference, this is similar to what is reported in reference, [25] which found a theoretical prediction around 3 times higher than the experimental data. This was attributed to inaccuracies in viscosity measurements coupled with a strong temperature dependence of these viscosities, which seems a reasonable hypothesis. This could explain why the bigger differences were observed for experiments at $180^{\circ} \mathrm{C}$, where the higher viscosities are measured, and where the Carreau-Yasuda model had to be used, introducing uncertainties in the measurements of both viscosities. The commercial extrusion grades used here for PS and PMMA might also explain these results, since they are rather more polydisperse (with more complex rheological dependence) than typical laboratory grades usually used for these studies. Possible confinement effects on the rheological behavior of the polymers have also not been taken into account. Moreover, the value of $\theta_{e}$ also remains questionable: taking 0.2 (as in reference [24]) instead of 0.4 , the difference would decrease from a factor 8 to 

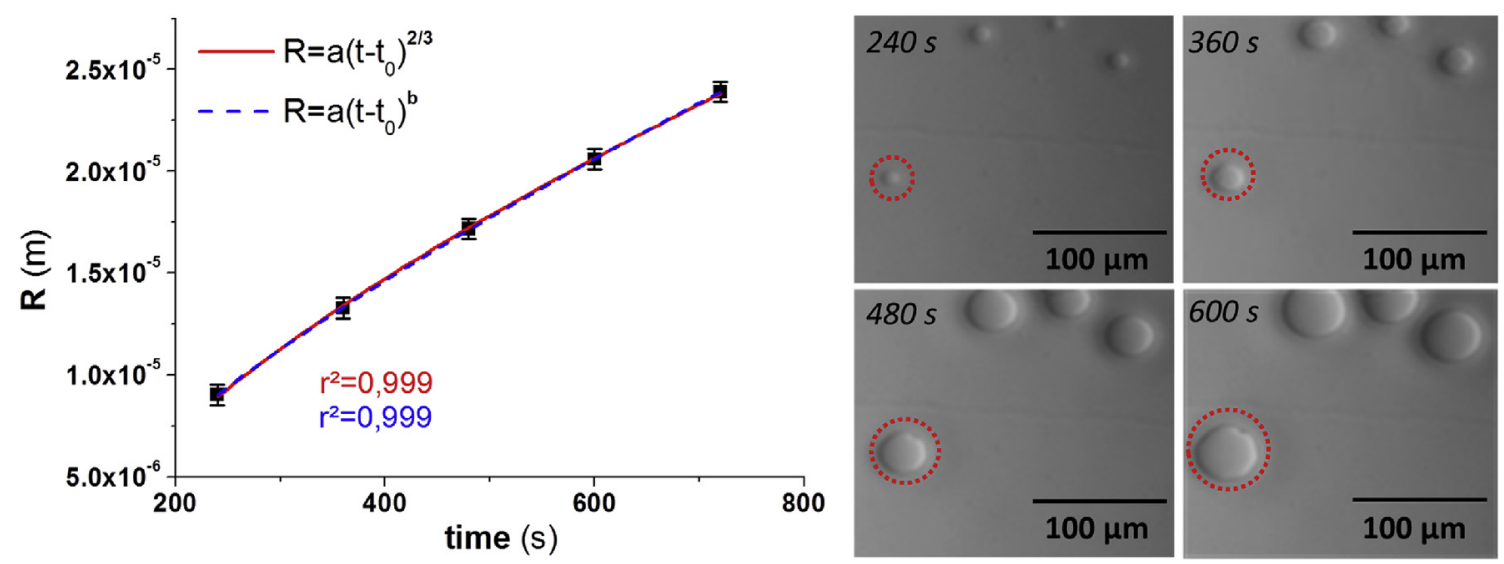

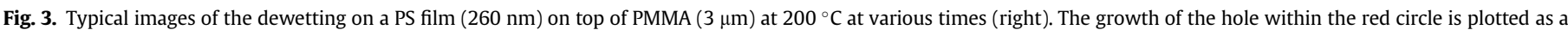

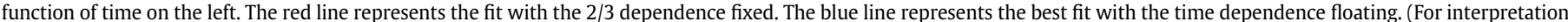
of the references to colour in this figure legend, the reader is referred to the web version of this article.)

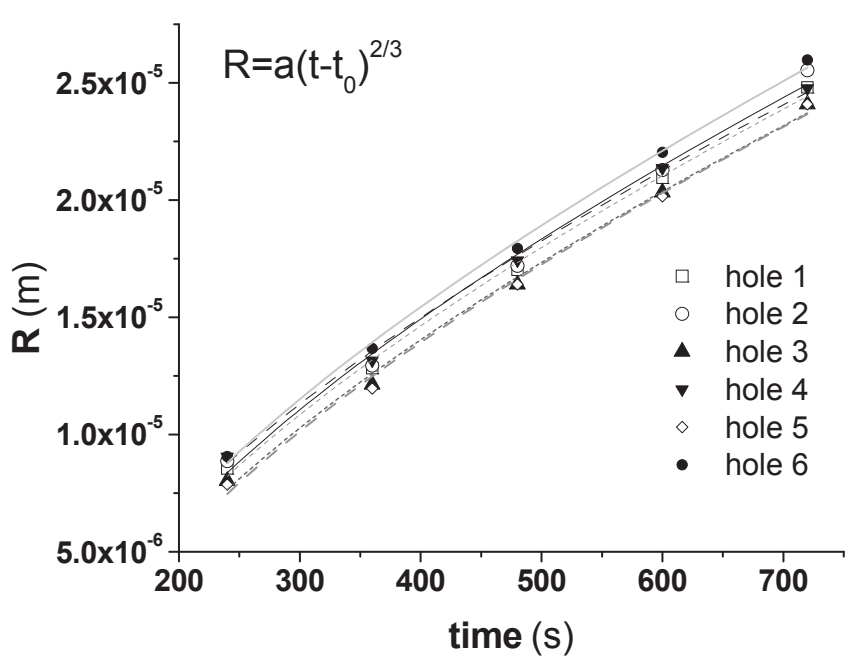

Fig. 4. Radius as a function of time for 3 holes on 2 different samples at the same experimental conditions $\left(\mathrm{T}=200{ }^{\circ} \mathrm{C}, \mathrm{d}_{\mathrm{PS}}=260 \mathrm{~nm}, \mathrm{~d}_{\mathrm{PMMA}}=3 \mu \mathrm{m}\right)$. Solid lines are fits following equation (4).

a factor 6. In Refs. [24], one can also note that the viscosity of the thin film also slightly influences the growth speed which is not predicted by equation (3). Finally, as suggested above, the out-ofequilibrium state of the polymer chains in the film and its effect on the dewetting might impact the dewetting kinetics.

Several experimental parameters were then varied: namely the temperature, the film and substrate thicknesses, and the viscosity of the substrate. Main results are presented in Fig. 5. We chose to represent in Fig. 5 one representative hole for each experimental condition. However, note that the values given for the fits in the figure are the mean values of the (at least) 6 holes fitted.

The trends are as expected: the growth speed increases when the temperature increases, e.g. when the viscosity of the substrate decreases. The film thickness dependence is small (1/3 exponent) which means that with a film 5 times thicker, the dewetting speed should be only 1.7 times lower, and only 1.2 with a film 2 times thicker. This corresponds well to what is measured for $120 \mathrm{~nm}$ and $260 \mathrm{~nm}$ films. However, the $50 \mathrm{~nm}$ films exhibit a slightly lower measured dewetting speed than expected. This could be due to the nucleation of too many holes which interact with others (leading to coalescence of the holes in droplets), leading to a rapid global dewetting of the PS film and unprecise measurement of the growth speed than for thicker films, as already shown in Ref. [25]. As expected, the growth speed also increases when the thickness of the substrate increases.

To summarize the results, we can plot the experimental values for $a\left(a_{\text {exp }}\right)$ as a function of the theoretical prediction $\left(a_{\text {theo }}=\left(\frac{\gamma^{2} d_{\mathrm{PMMA}}^{2} \theta_{e}}{\eta_{\mathrm{PMMA}} d_{\mathrm{PS}}}\right)^{1 / 3}\right)$ for all the experimental conditions tested, as shown in Fig. 6. The data points fall all rather well on the same master curve, giving an average difference between the experimental and theoretical value of a factor of 6.5 for all the parameters studied. From these results and previous studies in the literature [25], the existence of a neglected prefactor in equation (4) may then be asked.

It is worth noting that complementary dewetting experiments were performed at $200{ }^{\circ} \mathrm{C}$ for $260 \mathrm{~nm}$ PS films on $12 \mu \mathrm{m}$ thick and $>100 \mu \mathrm{m}$ thick PMMA VM100 substrates. In these cases, the substrate is substantially thicker than the rim size, and a constant velocity should be expected (viscous regime) [21,23], following equation (5) (equation (5))

$v=\left(\frac{\gamma}{\eta_{\text {PMMA }}}\right) \theta_{e}^{2}$

$\gamma$ being the effective surface tension defined above. For this experimental condition, indeed, the best fit for the exponent is $\sim 0.90$, fairly different from 0.7 found for the other experimental conditions. Fixing this parameter at a value of 1 , we obtain a mean value for the speed of $6.9 \times 10^{-8} \mathrm{~m} \mathrm{~s}^{-1}$ and $t_{0}$ around $30 \mathrm{~s}$ for the $12 \mu \mathrm{m}$ thick substrate, and very similarly, $8.6 \times 10^{-8} \mathrm{~m} \mathrm{~s}^{-1}$ with $t_{0}$ around $80 \mathrm{~s}$ for the $>100 \mu \mathrm{m}$ ones. The theoretical speed using equation (5) is $2.5 \times 10^{-7} \mathrm{~m} \mathrm{~s}^{-1}$, this time only around 3 times higher as the measured speed. It should be noted that in this thick substrate regime, the speed is much higher than in the regime when $d_{\text {PMMA }}$ is comparable with the size of the rim. Using equation (3) and the obtained value for $t_{0}$ in the same experimental conditions $\left(200{ }^{\circ} \mathrm{C}, d_{\mathrm{PS}}=260 \mathrm{~nm}\right)$, we can get an estimate of the maximum speed for $d_{\text {PMMA }}=3 \mu \mathrm{m}, v_{\max } \simeq 4 \times 10^{-8} \mathrm{~m} \mathrm{~s}^{-1}$.

\subsubsection{Liquid-solid dewetting}

We now move on to the case where $\eta_{\text {PMMA }}>\eta_{\mathrm{PS}} / \theta_{e}$. Here the dewetting is those of a liquid on a "solid"-like substrate (even though PMMA is actually in a molten state). In that case, the regime is viscous and the growth of the hole is controlled by the competition of capillary forces and viscous flow of the film. The radius of 

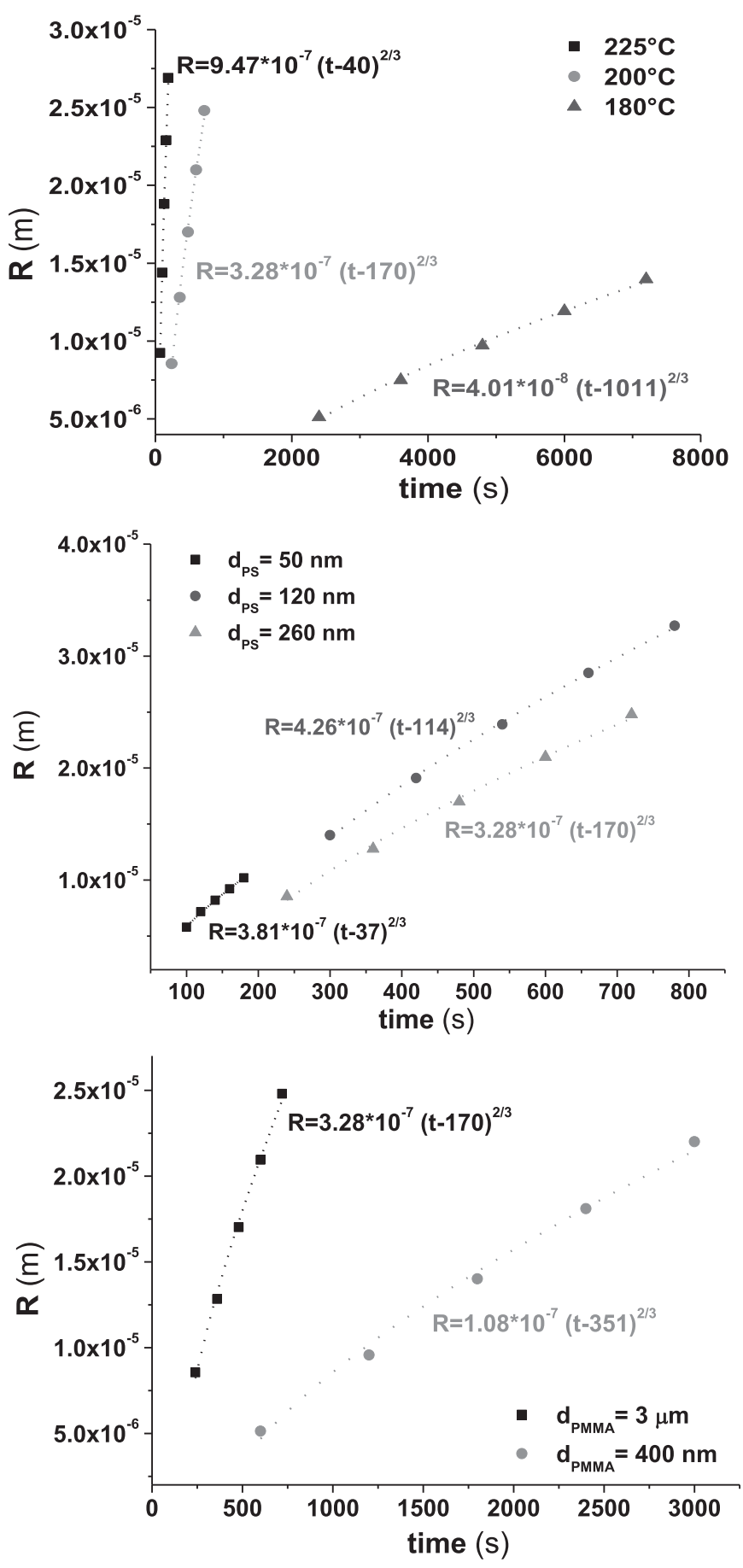

Fig. 5. Typical variations of the holes radius as a function of time for several experimental conditions. Top plot: different temperatures, $\mathrm{d}_{\mathrm{PS}}=260 \mathrm{~nm}, \mathrm{~d}_{\mathrm{PMMA}}=3 \mu \mathrm{m}$. Middle plot: different $\mathrm{d}_{\mathrm{PS}}, \mathrm{T}=200{ }^{\circ} \mathrm{C}, \mathrm{d}_{\text {PMMA }}=3 \mu \mathrm{m}$. Bottom plot: different $\mathrm{d}_{\text {PMMA }}$, $\mathrm{d}_{\mathrm{PS}}=260 \mathrm{~nm}, \mathrm{~T}=200^{\circ} \mathrm{C}$.

the growing hole is predicted to grow linearly with time [21,23], e.g. $R=v t$ with $v$ following equation (6) (equation (6)).

$v=\frac{1}{12 \ln \sqrt{2}} \frac{\gamma_{P S}}{\eta_{P S}} \theta_{e}^{3}$

In this study, this is the case for the PMMA V825T at $200{ }^{\circ} \mathrm{C}$ (at $225^{\circ} \mathrm{C}$ the dewetting condition is liquid-liquid and similar results as with PMMA VM100 are obtained).
Results are presented in Fig. 7. As previously, the growth of one typical hole is presented, and the values for the fits are the average values for at least 6 holes. First, it appears here that the best fit is also obtained for an exponent around 0.9 , close to 1 as predicted by equation (6). Then, a surprising slight dependence of the speed with the thickness of the substrate is observed $\left(\sim d_{\text {PMMA }}^{1 / 3}\right)$. This may be due to the fact that in these experimental conditions, we are still in the crossover regime between liquid-liquid and liquid-solid dewetting, since $\eta_{0}$ PMMA v825T $\sim 2 \eta_{0}$ PS $1340 / \theta_{e}$ (liquid-solid is predicted if $\eta_{0}$ PMMA V825T $>\eta_{0}$ PS $1340 / \theta_{e}$ ). However, at high thicknesses, the agreement between the theoretical model and the experimental results is similar to what has been found for the liquid-liquid dewetting with thick substrates, close to a factor of 2 $\left(v_{\text {theo }}=1.6 \times 10^{-8} \mathrm{~m} \mathrm{~s}^{-1}\right.$ here, using equation (6)). This might suggest again that a numerical prefactor is lacking in equation (3). For a given film, the speed is also much smaller in the liquid-solid regime than in the liquid-liquid one.

In conclusion, data obtained for experimental conditions scanning both the liquid-liquid and the liquid-solid regimes (and two sub-regimes depending on the substrate thickness for the liquid-liquid case) are in reasonable agreement with reported experimental studies and theoretical models from the literature. Brochard-Wyart models appear in semi-quantitative agreement, describing correctly the parameters affecting the trends of the dewetting kinetics. These results on commercial extrusion grades of polymers, with a large molar mass distribution and formulated with plasticizers, anti-oxidants etc, also demonstrate the robustness of the models.

\subsection{Trilayer system}

The experimental set-up was then used for trilayer systems. As for the previous case, let us first discuss some theoretical considerations. The most famous case of film bursting is those of soap films suspended in air. In that case, a constant speed where capillary drive balances with inertia is expected and has been measured already almost 50 years ago [33,34]. More recent studies focused on free-standing polymer films where viscous effects are dominant [35]. For these systems, no rim can be observed, contrary to soap films, and the growth of a hole is exponential. When the film is made thinner or the temperature is lowered closer to $T_{g}$, elasticity becomes the dominant parameter and the growth is then linear [36]. More relevant to our system is the case where a film bursts within a viscous environment [29,37]. In that case, the bursting proceeds also at a constant speed where capillary drive balances with viscous dissipation this time not in the film but inside the surrounding more viscous phase. Then, the capillary force per unit length which draws the rim $\gamma$ created is balanced with a viscous force. Treating the rim as a cylinder translating at a velocity $v$ in a surrounding phase of viscosity $\eta$, the viscous force per unit length should scale as $\eta v$ [29]. This leads to a constant opening velocity $v$ scaling as $\gamma / \eta$, which leads to equations (7) and (8) [29].

$v \sim \gamma / \eta$

$R=v t \sim \gamma t / \eta$

In our case, the relevant parameters would then be the interfacial tension $\gamma_{\text {PS/PMMA }}$ and the viscosity of the substrate $\eta_{\text {PMMA }}$ assuming the shearing due to the drawing of the rim occurs in the surrounding matrix.

Fig. 8 displays the appearance and growth of holes within the PS film in the PMMA matrix as a function of time.

The pictures of the holes appear very similar to those for the bilayer system, suggesting the existence of a rim (dark region at the 


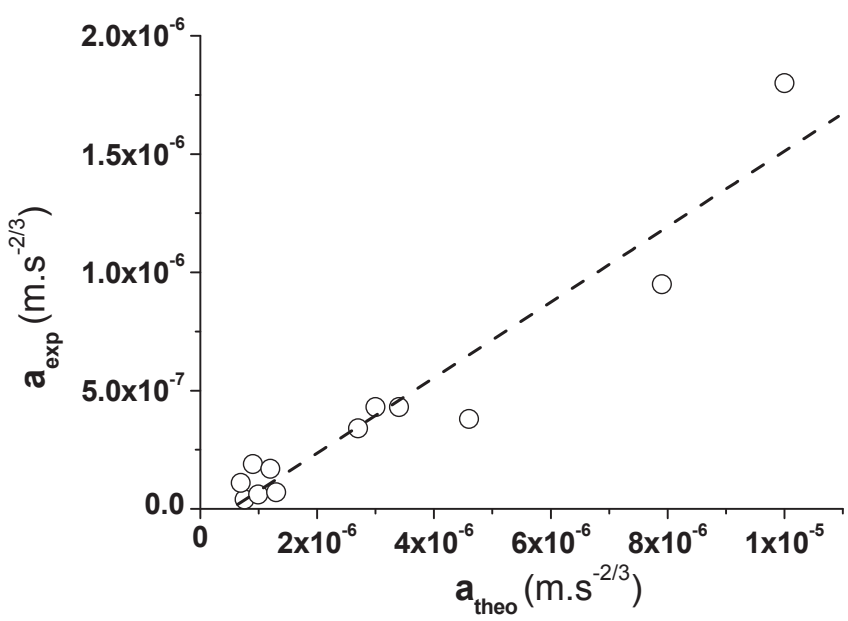

Fig. 6. Experimental values of the fitting parameter $a$ (in $R=a\left(t-t_{0}\right)^{2 / 3}$ ) as a function of the theoretical prediction obtained using equation (4) for the same conditions. Dashed line: linear fit.

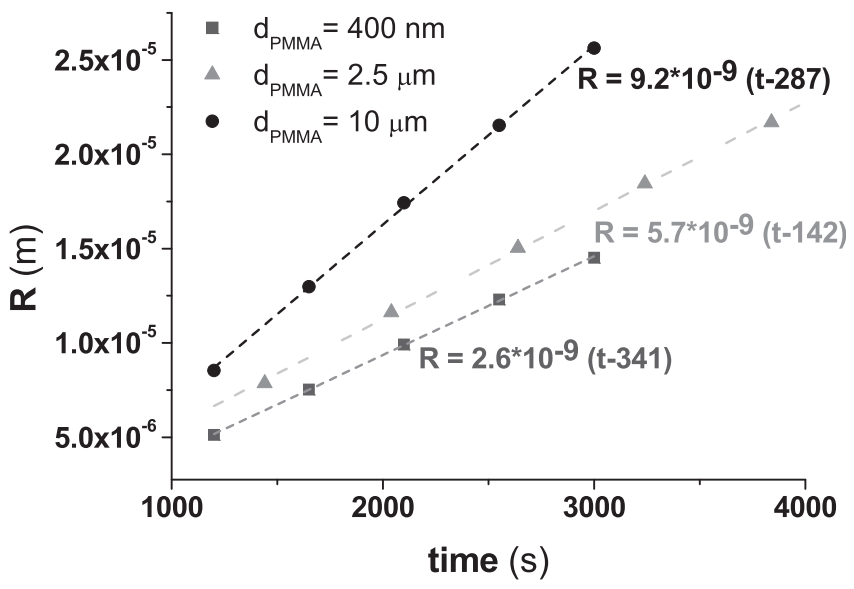

Fig. 7. Liquid-solid dewetting for $260 \mathrm{~nm}$ PS films on PMMA $825 \mathrm{~T}$ substrates at $200{ }^{\circ} \mathrm{C}$.

edge of the hole). This is consistent with what is observed in Ref. [29] as opposed to what is reported for free standing films $[35,36]$.

Concerning the hole growth, first, one can see that the best fit is obtained for an exponent between 0.8 and 0.9 (depending on the trilayers tested). Secondly, as for the bilayer system, it can be seen that the simple equation discussed above (equation (6)) fits well the data but that an "induction time" $t_{0}$ needs to be introduced. However the value obtained from the fit for this induction time is, in some cases, negative ( $-70 \mathrm{~s}$ in the example in Fig. 8), which has no physical meaning. It has been suggested that it might result from interplay between the different layers [27]. As stated in a recent paper on the onset of the instabilities in such thin films "symmetric sandwich" [28], the dewetting mechanism should be spinodal. In that case, $t_{0}$ should be minimal and identical for every hole [32]. However, Fig. 8 does not seem to confirm this statement (suggesting rather nucleation) and forcing the fit through 0 does not capture well the experimental data. This could be due that the theoretical velocity is calculated in the permanent regime, e.g. neglecting possible inertial transient dynamics. Unfortunately, our setup prevented us from capturing what happens during the initial stages of the bursting so it would not be reasonable to elaborate further on this. When the first image is taken, around $45 \mathrm{~s}$ after the beginning of the experiment, holes were visible in the cases where $t_{0}$ is negative, which only allows us to say that $t_{0}$, if it exists, is smaller than $45 \mathrm{~s}$.

Similarly to what we have done for the bilayers, several holes on different samples were monitored and different experimental conditions were studied. The main results are presented in Figs. 9 and 10 .

First, as predicted by the simple model adapted from Reyssat and Quéré [29], the thickness of the PS film does not modify the bursting speed (see Fig. 9, left). The expected dependence on the temperature (eg on the viscosity of the surrounding matrix) is also observed (Fig. 9, right). Similar results were also obtained using PMMA V825T as a matrix, at $200{ }^{\circ} \mathrm{C}$ and $225{ }^{\circ} \mathrm{C}$. Second, the experimental speed is extremely close to the theoretical speed calculated using the simple scaling in equations (7) and (8): a difference of less than $50 \%$ is observed on average, for all conditions studied. For example, at $200{ }^{\circ} \mathrm{C}$, the predicted speed is $8.8 \times 10^{-8} \mathrm{~m} \mathrm{~s}^{-1}$ for PMMA VM100. Finally, if we compare with the bilayer systems, we can also remark that the (possible) induction time is smaller and the speed higher in the trilayer case.

Then, the effect of the thickness of PMMA on the bursting speed was studied for both PMMA (Fig. 10). Interestingly, a slower kinetics is observed for thin PMMA layers ( $400 \mathrm{~nm}$ ) embedding a $270 \mathrm{~nm}$ PS film. For thicker PMMA layers, however, the bursting speed increases and seems to reach a constant value (an average of $9.3 \times 10^{-8} \mathrm{~m} \mathrm{~s}^{-1}$ is obtained for the trilayers with the PMMA VM100, and $1.46 \times 10^{-8} \mathrm{~m} \mathrm{~s}^{-1}$ for the trilayers with the PMMA V825T) close to the theoretical one $\left(8.8^{*} 10^{-8} \mathrm{~m} \mathrm{~s}^{-1}\right.$ for the VM100, $1.5 \times 10^{-8} \mathrm{~m} \mathrm{~s}^{-1}$ for the V825T).

This thickness effect might be explained by the fact that the viscous dissipation within the PMMA occurs in a certain volume around the film (following, on first approximation, a Poiseuille flow), which means that this dissipation is slowed down with the thinner PMMA layers and the glass slides below and above (see Fig. 2). This critical thickness should depend on the viscosity, as is suggested by Fig. 10 (the volume of PMMA needed should decrease when the viscosity is increased). Negative induction times which are observed for the thinner PMMA layers, when the dynamics is slowed down, could also suggest that our simple model does not capture correctly these confinement effects. It is worth noting here that the values obtained even for positive induction times are noisier than for the bilayer system (for example, for the $270 \mathrm{~nm}$ PS film within $2.5 \mu \mathrm{m}$ V825T layers, $t_{0}=12 \pm 130 \mathrm{~s}$ ). Finally, it should be noted that for $400 \mathrm{~nm}$ PMMA layers, in both the bilayer and trilayer case, dewetting of the PMMA on the glass slide could also occur, as has been studied by Xu et al. [38] However, with the polymers chosen and the experimental conditions of this study, it is always much slower than the dewetting of the PS film.

Going back to the "unconfined matrix" conditions, we plotted for all the conditions studied for our buried PS film (within PMMA VM100 at 180,200 and $225{ }^{\circ} \mathrm{C}$ and PMMA V825T at $200{ }^{\circ} \mathrm{C}$ and $225^{\circ} \mathrm{C}$ ), $v / \gamma$ as a function of $1 / \eta$ (see Fig. 11). A linear regression fits quite nicely the data for over two decades, as predicted by the simple model (equation (7)), with a slope close to 1 .

To conclude, when comparing these results to multilayer coextrusion, we noticed that for PS/PMMA multilayer films with PS layers below $100 \mathrm{~nm}$ and PMMA layers on the order of few hundreds of nm, significant layer breakup was only observed when trying to obtain PS thicknesses below $\sim 30 \mathrm{~nm}$. However the characteristic time scales of the process (e.g. the residence time in the feedblock containing the multiplying elements) is on the order of 2 min with an extrusion temperature of $200^{\circ} \mathrm{C}$ or $225^{\circ} \mathrm{C}$. After $2 \mathrm{~min}$, our "model" systems all displayed, even the thicker ones $\left(d_{\mathrm{PS}} \approx 260 \mathrm{~nm}\right)$, as discussed previously, significant breakups (many holes larger than $10 \mu \mathrm{m}$ in diameter) in the "static" conditions of the conducted experiments. 

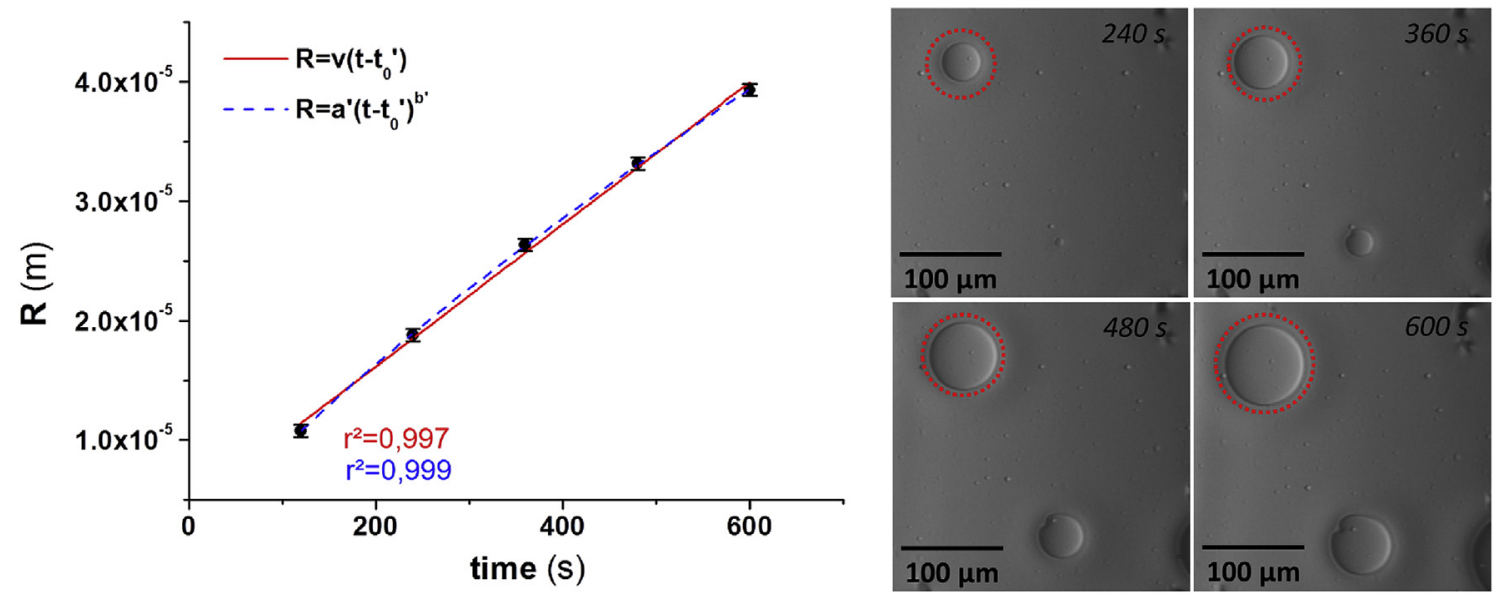

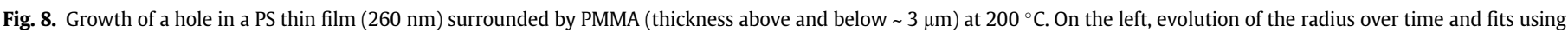
equation (7).
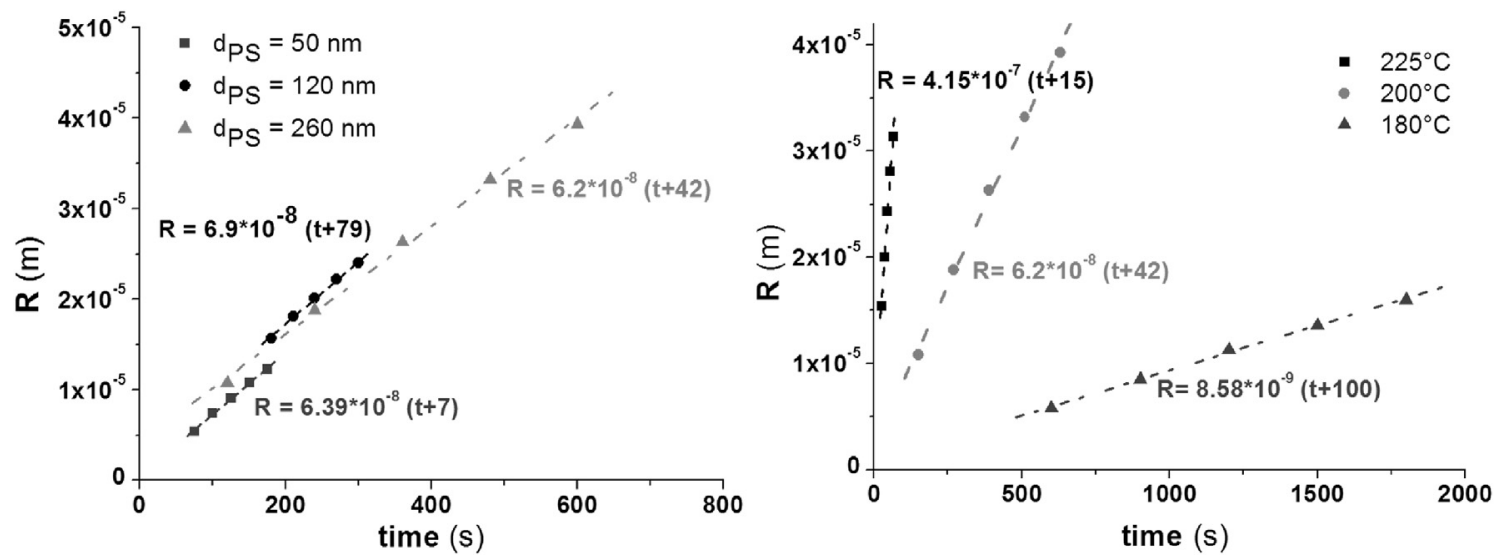

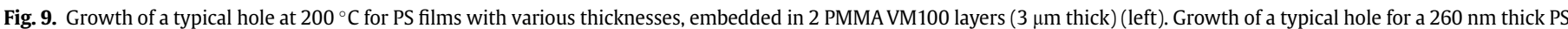
film embedded in $3 \mu \mathrm{m}$ thick PMMA layers at various temperatures (right).
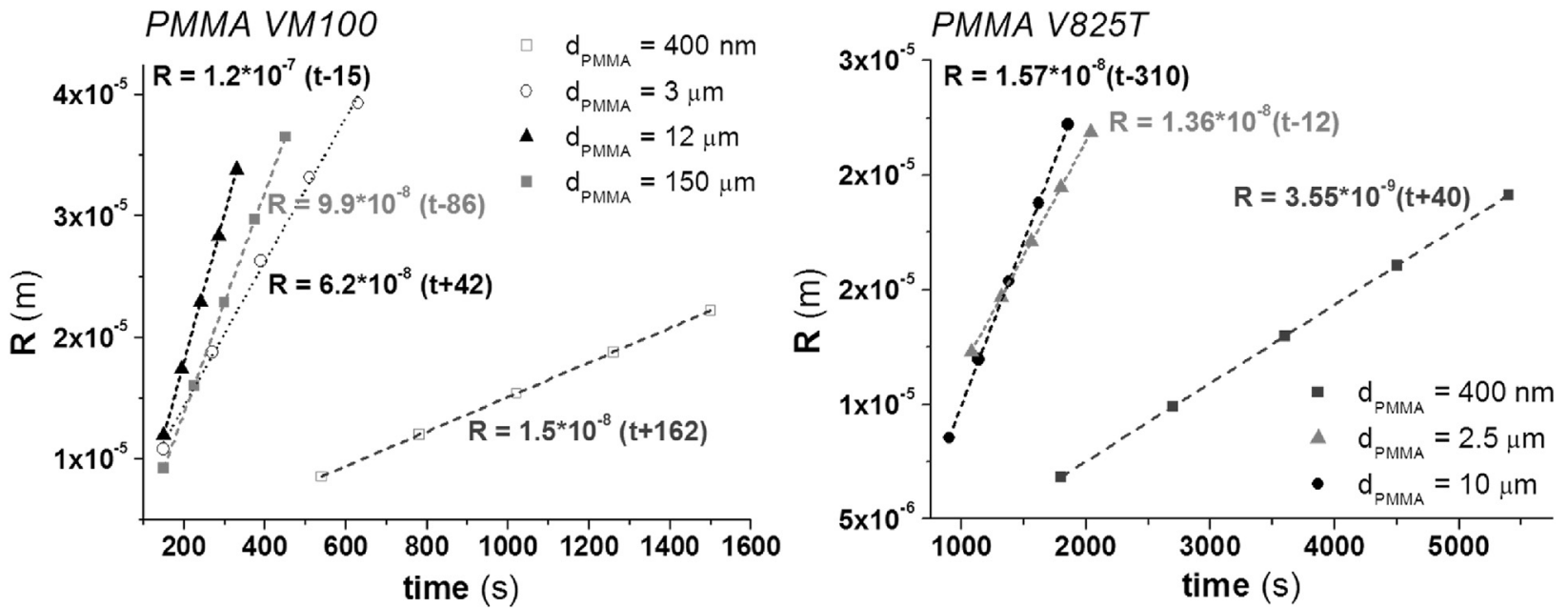

Fig. 10. Evolution of the bursting speed of a $270 \mathrm{~nm}$ PS film as a function of the PMMA surrounding layers thicknesses (left: PMMA VM100, right: PMMA V825T) at $200{ }^{\circ} \mathrm{C}$.

Contrary to what is seen in multilayer coextrusion, our "model" system also displays no differences for the breakup of PS films of different thicknesses. This suggests strongly that, rather counterintuitively, the elongation and shear forces induced by the flow in the multiplying elements during the extrusion actually act as stabilizing factors until a critical thickness ( $30 \mathrm{~nm}$ for PS/PMMA systems) is reached, where van der Waals forces become too strong and cause spontaneous break-up of the layers. A stabilization of van der Waals- 


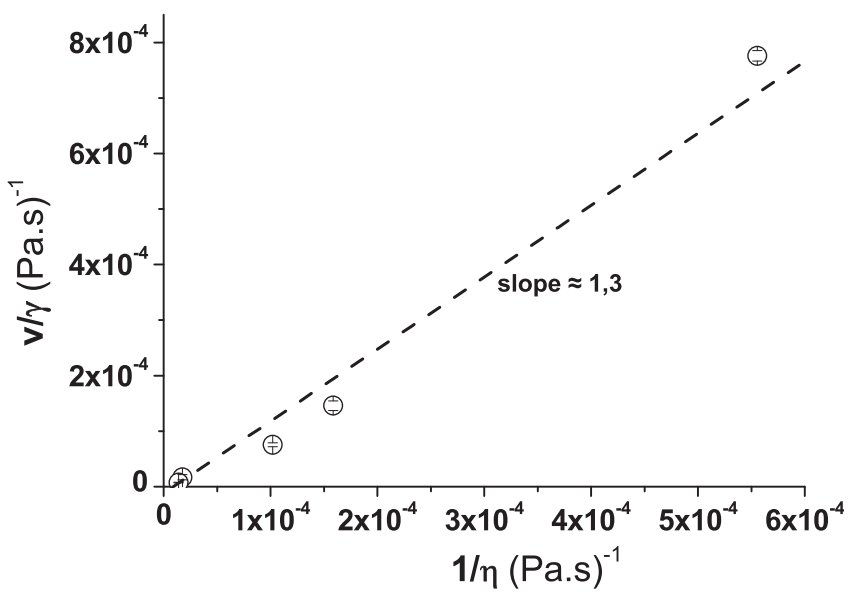

Fig. 11. $v / \gamma$ as a function of $1 / \eta$ for all the conditions studied. Dashed line: linear fit of the experimental data.

driven rupture of thin films by shearing flows has already been reported in the literature $[39,40]$.

\section{Conclusion}

We developed an experimental setup to study in situ the dewetting of polymer thin films. This setup was successfully used to follow the dewetting of a thin polymer film on an immiscible polymer substrate for several regimes depending on the viscosity ratio of the two polymers and on the thickness of the substrate. It was then adapted to monitor for the first time the rupture of a thin polymer film embedded in an immiscible polymer matrix. The observed behavior is well captured for all experimental conditions (with the exception of $d_{P M M A} \sim d_{P S}$ where a slower kinetics is measured) by a simple model balancing viscous and capillary forces in the system. The bursting speed is then simply the ratio between the viscosity of the substrate (where the dissipation occurs) and the interfacial tension between the two polymers. This study also can shed new light that will help mastering an innovative process for the design of new polymeric materials at an industrial scale, e.g. multilayer coextrusion. Future work will be based on this study and the growth of holes will be studied in situ during shearing and/or elongating of the sample. The confinement effect observed for the trilayer systems will also be the subject of further studies, by varying more systematically the thickness of the substrate below $\sim 1 \mu \mathrm{m}$ in order to quantify its influence on the bursting speed. Finally we aim at looking at 5-layer systems where the PMMA layers are confined by PS since it can be important in the case of multilayer films. An exact understanding of this "critical thickness" for PS/PMMA systems obtained via multilayer coextrusion also remains an open question.

\section{Acknowledgment}

The authors would like to thank Liliane Léger for fruitful discussions during the genesis of this project, and Thomas Salez for fruitful discussions during the writing of the manuscript. They also would like to acknowledge financial support from the Agence Nationale de la Recherche (ANR) under contract ANR-11-BS040030 [WAFPI] and from the Investissements d'Avenir via the Isocel program.

\section{References}

[1] W.A. Braunecker, K. Matyjaszewski, Prog. Polym. Sci. 32 (1) (2007) 93-146.

[2] N.E. Kamber, W. Jeong, R.M. Waymouth, R.C. Pratt, B.G.G. Lohmeijer, J.L. Hedrick, Chem. Rev. 107 (12) (2007) 5813-5840.

[3] K. Wang, F. Chen, Z. Li, Q. Fu, Prog. Polym. Sci. 39 (5) (2014) 891-920.

[4] Schrenk, W. J. Method for multilayer coextrusion. US3773882 A, 1973.

[5] E. Baer, A. Hiltner, H.D. Keith, Science 235 (4792) (1987) 1015-1022.

[6] J.M. Carr, D.S. Langhe, M.T. Ponting, A. Hiltner, E. Baer, J. Mater. Res. 27 (10) (2012) 1326-1350.

[7] D. Jarus, A. Hiltner, E. Baer, Polym. Eng. Sci. 41 (12) (2001) 2162-2171.

[8] R.Y.F. Liu, T.E. Bernal-Lara, A. Hiltner, E. Baer, Macromolecules 37 (18) (2004) 6972-6979.

[9] M. Ponting, A. Hiltner, E. Baer, Macromol. Symp. 294 (1) (2010) 19-32.

[10] H.P. Wang, J.K. Keum, A. Hiltner, E. Baer, B. Freeman, A. Rozanski, A. Galeski, Science 323 (5915) (2009) 757-760.

[11] X. Li, G.B. McKenna, G. Miquelard-Garnier, A. Guinault, C. Sollogoub, G. Regnier, A. Rozanski, Polymer 55 (1) (2014) 248-257.

[12] G. Miquelard-Garnier, A. Guinault, D. Fromonteil, S. Delalande, C. Sollogoub, Polymer 54 (16) (2013) 4290-4297.

[13] M. Boufarguine, A. Guinault, G. Miquelard-Garnier, C. Sollogoub, Macromol Mater. Eng. 298 (10) (2013) 1065-1073.

[14] S. Roland, G. Miquelard-Garnier, M. Gervais, A. Guinault, C. Sollogoub, Mater Today Commun. 6 (2016) 37-43.

[15] Y. Lin, A. Hiltner, E. Baer, Polymer 51 (18) (2010) 4218-4224.

[16] T.E. Bernal-Lara, R.Y.F. Liu, A. Hiltner, E. Baer, Polymer 46 (9) (2005) 3043-3055.

[17] R. Adhikari, W. Lebek, R. Godehardt, S. Henning, G.H. Michler, E. Baer, A. Hiltner, Polym. Adv. Technol. 16 (2-3) (2005) 95-101.

[18] K. Ho, J.S. Lee, N. Viriyabanthorn, C. Sung, C.M.F. Barry, J.L. Mead, Interfacial Instabilities in Multilayer Extrusion, Nano Science \& Technology Inst, Cambridge, 2004, pp. 468-471.

[19] C.D. Han, R. Shetty, Polym. Eng. Sci. 18 (3) (1978) 180-186.

[20] W.J. Schrenk, N.L. Bradley, T. Alfrey, H. Maack, Polym. Eng. Sci. 18 (8) (1978) 620-623.

[21] F. Brochard-Wyart, P. Martin, C. Redon, Langmuir 9 (12) (1993) 3682-3690.

[22] G. Reiter, Phys. Rev. Lett. 68 (1) (1992) 75-78.

[23] G. Krausch, J. Phys. Condens. Matter 9 (37) (1997) 7741-7752.

[24] S. Qu, C.J. Clarke, Y. Liu, M.H. Rafailovich, J. Sokolov, K.C. Phelan, G. Krausch, Macromolecules 30 (12) (1997) 3640-3645.

[25] C. Wang, G. Krausch, M. Geoghegan, Langmuir 17 (20) (2001) 6269-6274.

[26] P. Lambooy, K.C. Phelan, O. Haugg, G. Krausch, Phys. Rev. Lett. 76 (7) (1996) 1110-1113.

[27] J.P. de Silva, M. Geoghegan, A.M. Higgins, G. Krausch, M.O. David, G. Reiter Phys. Rev. Lett. 98 (26) (2007) 4.

[28] J.P. de Silva, F. Cousin, A.R. Wildes, M. Geoghegan, M. Sferrazza, Phys. Rev. E 86 (3) (2012) 4.

[29] E. Reyssat, D. Quéré, Europhys. Lett. 76 (2) (2006) 236-242.

[30] L.J. Xue, B.H. Hu, Y.C. Han, J. Chem. Phys. 129 (21) (2008) 6.

[31] S. Wu, J. Phys. Chem. 74 (3) (1970) 632-638.

[32] R. Seemann, S. Herminghaus, K. Jacobs, J. Phys. Condens. Matter 13 (21) (2001) 4925.

[33] S. Frankel, K.J. Mysels, J. Phys. Chem. 73 (9) (1969) 3028-3038.

[34] W.R. McEntee, K.J. Mysels, J. Phys. Chem. 73 (9) (1969) 3018-3028.

[35] G. Debrégeas, P. Martin, F. Brochard-Wyart, Phys. Rev. Lett. 75 (21) (1995) 3886-3889.

[36] J.H. Xavier, Y. Pu, C. Li, M.H. Rafailovich, J. Sokolov, Macromolecules 37 (4) (2004) 1470-1475.

[37] A. Eri, K. Okumura, Phys. Rev. E 82 (3) (2010) 030601.

[38] L. Xu, T.F. Shi, L.J. An, J. Chem. Phys. 130 (18) (2009) 7.

[39] S.K. Kalpathy, L.F. Francis, S. Kumar, J. Colloid Interface Sci. 348 (1) (2010) 271-279.

[40] M.J. Davis, M.B. Gratton, S.H. Davis, J. Fluid Mech. 661 (2010) 522-539. 